\title{
CSResearch Square \\ Microplastic Pollution In Estuarine Ecosystem At Sungai Laloh, Pasir Putih
}

\author{
Nurul Atikah Mohd Amin ( $\nabla$ n.atikah@utm.my ) \\ Universiti Teknologi Malaysia https://orcid.org/0000-0002-4232-8704 \\ Shamila Azman \\ Universiti Teknologi Malaysia
}

Research Article

Keywords: microplastic, estuary, green mussel, sediment and ATR FT-IR

Posted Date: February 9th, 2022

DOI: https://doi.org/10.21203/rs.3.rs-1331548/v1

License: (9) This work is licensed under a Creative Commons Attribution 4.0 International License. Read Full License 


\section{Abstract}

This paper presents the characteristics and trends of microplastic pollution in the estuarine ecosystem at Sungai Laloh, Pasir Putih. The sample collected were green mussels and sediment located at two different sampling point. A comparison of similar total weight was made for wild mussel and cultured mussel. The method involved the pre-treatment of green mussels and sediment sample, followed by digestion and analysis. In pre-treatment, the aquatic specimen and sediment undergo non-toxic density separation with the used of $1.2 \mathrm{~kg} / \mathrm{L}$ sodium chloride $(\mathrm{NaCl})$. The digestion was made by adding $35 \%$ $(\mathrm{v} / \mathrm{v})$ hydrogen peroxide $\left(\mathrm{H}_{2} \mathrm{O}_{2}\right)$ and incubated for 24 to 48 hours by using incubator shaker at of $50^{\circ} \mathrm{C}$ and $80 \mathrm{rpm}$. Analysis was conducted by using stereomicroscope and Attenuated Total Reflection Fourier Transform Infrared Spectroscopy (ATR FT-IR). In addition, SPSS statistical software was used to determine the significant difference between wild mussel and cultured mussel. Results show that microplastic fragment found abundant in mussel while microplastic fibers were found in sediment. The types of polymer microplastic found were polyethylene (PE), polypropylene (PP), polyethylene terephthalate (PET), ethylene vinyl acetate (EVA) and nylon (all polyamides). In comparison based on percentage of abundance, cultured mussel was the most polluted with microplastic.

\subsection{Introduction}

Microplastic pollution is serious environmental problem of marine debris due to its difficulty to decompose which can be up to hundreds of years. Currently, airborne microplastic has been observed in atmosphere which includes indoor and outdoor environments. The microplastics can be through wind from the ocean and surrounding land areas. In 2017, the production of plastic reached 348 million metric tons. The production of plastic worldwide has continued to increase at approximately $3 \%$ each year. From the amount, only $3 \%$ of plastic used were recycled. Based on the trends, it is estimated that on 2050 approximately 67.8 million metric ton of plastics will be at the environment or landfill (Ebere et al., 2019). Microplastic can be recognized with size less than $5 \mathrm{~mm}$ in diameter (Dowarah et al., 2020; Wagner et al., 2014; Waite et al., 2018; Wu, 2020). Besides, this marine debris can be categorized based on its various sizes either nano, micro, meso, macro and megaplastics.

The smaller size of microplastic might be ingested by aquatic life which includes plankton, fish, mussel, seashell, crab and other animal that life on land. Plastic that is difficult to decompose cause harm to animal and human health as the food chain contained of the aquatic life (Han, 2020). It has been classified onto primary microplastic (personal care and cosmetic products) and secondary microplastic (fragmentation from chemical and biological interaction) (Defu et al., 2018). Some of the primary microplastic is microbead which originated from personal care. Microbeads usually have white and opaque colors (Hu et al., 2019). In the ocean and rivers, the microplastic fragment from the synthetic fiber usually come from fabric washing (Firdaus et al., 2020). Plastic which made up of polymer consisted of several types. The types of polymer microplastic are polyethylene (PE), polypropylene (PP), polystyrene (PS), polyvinylchloride (PVC), nylon (all polyamide), acrylonitrile butadiene styrene (ABS), cellulose acetate $(\mathrm{CA})$, polycarbonate $(\mathrm{PC})$, polyurethane $(\mathrm{PU})$, polymethyl methacrylate (PMMA), 
polytetrafluoroethylene (PTFE) and polyethylene terephthalate (PET) (Cai et al., 2019; Defu et al., 2018; Jung et al., 2018). Previous study has focused on characterizing microplastic pollution in freshwater, ocean, terrestrial environment and wastewater treatment plant (WWTP) (Wang et al., 2020). However, there is lack of information on microplastic pollution at the estuarine ecosystem in Malaysia (Athey, 2020).

The estuary is an enclosed body of water that mixes freshwater and saltwater from the sea $(\mathrm{Wu}, 2020)$. It is also connected between land and sea. The classification of estuary consisted of harbors, inlets, bays, lagoons, wetlands and swamps. Estuarine play an important role as the nursery of the ocean. Besides, it provides rich feeding ground for fish and birds. The animals located at estuaries ecosystem includes fish, crab, sea birds, marine worms, skunks and shellfish (mussel). From the previous research, polypropylene (PP) and polyethylene (PE) bring an impact to ragworm and fish (Revel et al., 2020). However, there is lack of information on microplastic trends in shellfish or mussel. Mussel which known as bivalves is a valuable organism to determine the different levels of pollutants in the environment. In addition, mussel can be used as global bioindicator of microplastics (Dowarah et al., 2020). The mussel can act as a filter feeder which traps and accumulate the microplastic pollutant due to their low excretion rates (Su et al., 2018). Rather than aquatic life, sediment sample has been used to determine the microplastic pollutant due to its different density. Previous study show that from collected sediments, type of film microplastic found abundance at rivers strait of Johor (Shazani et al., 2018). However, the type of plastic ingested by marine might be different.

In this study, microplastic pollution in estuarine ecosystem was investigate at Sungai Laloh, Pasir Putih. The objective of this study are to (1) identify the trends of microplastic present in the mussel and sediment sample at estuarine of Sungai Laloh; (2) determine the characteristic of microplastic present based on color and size; (3) identify the functional group of polymer microplastic present; (4) compare abundance of microplastic pollution from similar total weight between wild mussel and cultured mussel. The scope of this study is covered on the mussels and sediments located within the research area from October to November 2020. In situ parameters were analysis for DO, pH, temperature, salinity, conductivity and turbidity. Lab analysis includes digestion, separation and identification using microscope and ATR FT-IR.

\subsection{Methods}

The samples collected were mussels and sediments. The methods involve three-step process which are pre-treatment, digestion and analyze by using high-end instruments. The characterization of microplastic present involves identification of size, color and their type. Besides, a comparison is made for wild and cultured mussel with amount approximately $350 \mathrm{~g}$ weight for each wet mussel from different sizes. Finally, correlation is made to determine the significant different of microplastic present in both mussels. All materials and methods used are described in Figure 1.

\subsection{Sample collection}


The sample was collected from two sampling point at estuarine ecosystem nearest to Sungai Laloh, Pasir Putih as show in Figure 2. The first point is located of cultured mussel with global positioning system (GPS) coordinate $1^{\circ} 25^{\prime} 59.178^{\prime \prime} \mathrm{N} 103^{\circ} 55^{\prime} 44.238^{\prime \prime} \mathrm{E}$. The second point is located at GPS coordinate $1^{\circ} 25^{\prime} 59.0^{\prime \prime} \mathrm{N} 103^{\circ} 54^{\prime} 25.1^{\prime \prime} \mathrm{E}$ that locate wild mussel. The main activities within this area involve industrial activities and seafood restaurant. Before collection, safety precaution was taken by wear life jacket and suitable personal protective equipment (PPE). All types of plastic container for the storage of sample are avoided to prevent contamination. Initially, the water quality was measured by using YSI ProPlus. The parameters involved are dissolved oxygen (DO), $\mathrm{pH}$, temperature, salinity, and conductivity. Turbidity was measured using portable turbidimeter HACH 2100Q. Next, 100 mussels of different size range were collected and stored in sampling box. For the sediment, $300 \mathrm{~g}$ of sample were collected using the Ekman dredge sediment sampler (Wu, 2020). The collected sample were stored at temperature $4^{\circ} \mathrm{C}$. The sample was brought to the lab for sample preparation and undergo pre-treatment process. The next part was conducted in close area to prevent airborne microplastic contamination.

\subsection{Pre-treatment process}

Initially, the size (length and width) and weight of mussel be measured by using vernier calipers and analytical balance as shown in Figure 3. The extraction of microplastic was made through density separation for mussels and sediment samples. In this process, the density of $1.2 \mathrm{~kg} / \mathrm{L}$ saturated sodium chloride solution ( $\mathrm{NaCl}$ ) be used which also a non-toxic technique (Deng et al., 2020; Yulin et al., 2019). Eleven batches of wet mussel that has been removed from its shell was immersed and shake vigorously in separated $250 \mathrm{~mL}$ conical flask. The triplicate amount of $25 \mathrm{~g}$ sediment sample was taken for pretreatment. In this method, less dense of microplastic cause it to float in the upper surface of solution. Usually, PP, PE, PET and nylon have density of $0.946 \mathrm{gcm}^{-3}, 0.940 \mathrm{gcm}^{-3}, 1.38 \mathrm{gcm}^{-3}$ and $1.15 \mathrm{gcm}^{-3}$ respectively (Quinn et al., 2017).

\subsection{Digestion of sample}

The sample was digested to breakdown the soft tissue. Previous study stated that digestion with hydrogen peroxide $\left(\mathrm{H}_{2} \mathrm{O}_{2}\right)$ was the most effective technique (Waite et al., 2018; Yulin et al., 2019). However, this technique can destroy organics that present in the sample. A large amount of $\mathrm{H}_{2} \mathrm{O}_{2}$ was required in the digestion method. $100 \mathrm{~mL}$ of $35 \% \mathrm{v} / \mathrm{v} \mathrm{H}_{2} \mathrm{O}_{2}$ was added into each sample. Then, it is placed inside an incubator shaker to be digested. The incubator is set at temperature $50^{\circ} \mathrm{C}$ and rotation speed $80 \mathrm{rpm}$ for about 24 to 48 hours until the soft tissues breakdown completely. Then, the sample was filtered by using vacuum pump and Whatman GF/C (1.2 $\mu \mathrm{m}$ glass microfiber filters) as shown in Figure 4 (Alam et al., 2019).

\subsection{Analysis technique}

The details of the analysis method are explained in the next section.

\subsubsection{Observe under stereomicroscope}


A stereomicroscope HSZ 600 series as shown in Figure 5 was used in this study. It is used to identify and determine the characteristic of microplastic present by observe under the microscope. The characterization of microplastic involved identification the color and size (Zuo et al., 2020). This microscope can be used with turn on the up or bottom light which provided better light intensity of the image capture. The focusing knob be adjusted until clear image found. In this study, $12 x$ to $15 x$ optical magnification be used. The length of the microplastic present was measured by using i-Solution image analysis software.

\subsubsection{Identification the functional group from ATR FT-IR absorption bands}

A Perkin Elmer Attenuated Total Reflection Fourier Transform Infrared Spectroscopy (ATR FT-IR) used is shown in Figure 6 for wavelength 650 to $4000 \mathrm{~cm}-1$. Initially, the ATR diamond was cleaned with acetone followed by background scan to remove contamination. Each of the selected sample was placed at the diamond surface and compressed with a force of $100 \mathrm{~N}$ to ensure good contact between sample and ATR diamond. The absorption bands obtained was compared with previous findings to identify types of polymer microplastic present. This technique is also known as a non-destructive method where the sample can be used again after analysis (Cai et al., 2019; Melissa et al., 2018; Waite et al., 2018).

\subsection{Abundance of microplastic present in wild and cultured mussel}

The data collected was performed statistical analysis by using SPSS software to determine the significant differences between microplastic abundance in the mussel. The sample is statistically significant if $p \leq 0.05$ (Zuo et al., 2020).

\subsection{Results And Discussion}

The water quality data for both sampling location is show in Table 1. The size of collected mussel was shown in Table 2. Estuarine is saline condition with mixing of fresh and saltwater. During summer, the salinity of estuarine increase as the freshwater flow reduces. In higher saline condition, the amount of oxygen can dissolve in water is decrease. Mussel is the common aquatic animal that live in estuarine ecosystem. In Malaysia, mussels can live in condition with temperature between $26^{\circ} \mathrm{C}$ to $32^{\circ} \mathrm{C}$ (Nishida et al., 2003).

From the data, sampling Point 2 have highest salinity and conductivity $(29.19 \mathrm{ppt}$ and $49701 \mu \mathrm{S} / \mathrm{cm})$ compared to Point 1 as it is located far from freshwater body of Sungai Laloh. The suitable water salinity for mussel farming was reported between $27 \mathrm{ppt}$ to $35 \mathrm{ppt}$. In addition, sampling Point 2 show highest amount of turbidity which was 3.40 NTU compared to Point 1. It's also located nearest to industrial area in Pasir Gudang compared to Point 1 that is located at freshwater flow. From Table 2, the data obtained for mussel sample have difference size range. In this research, the cultured mussel was attached at the rope that tie with plastic container to make it float while wild mussel can be found attached to the bridge 
at nearest areas. The bigger size of mussel show that it has live more longer in the ecosystem, The growth of green mussel can be influenced by temperature, food source, salinity and competition for space. The high salinity condition and semi-enclosed bay was promote filtration rate of mussels (Tan, 2014).

Table 1

The water quality data measured from both sampling point.

\begin{tabular}{|llll|}
\hline \multicolumn{3}{|l}{ Sampling Point 1: cultured mussel } & \multicolumn{3}{l|}{ Sampling Point 2: wild mussel } \\
\hline Parameter & Result & Parameter & Result \\
\hline DO & $6.15 \mathrm{mg} / \mathrm{L}$ & $\mathrm{DO}$ & $6.22 \mathrm{mg} / \mathrm{L}$ \\
\hline $\mathrm{pH}$ & 6.29 & $\mathrm{pH}$ & 6.97 \\
\hline Temperature & $30^{\circ} \mathrm{C}$ & Temperature & $30^{\circ} \mathrm{C}$ \\
\hline Salinity & $28.33 \mathrm{ppt}$ & Salinity & $29.19 \mathrm{ppt}$ \\
\hline Conductivity & $48449 \mu \mathrm{s} / \mathrm{cm}$ & Conductivity & $49701 \mu \mathrm{s} / \mathrm{cm}$ \\
\hline Turbidity & $2.35 \mathrm{NTU}$ & Turbidity & $3.40 \mathrm{NTU}$ \\
\hline
\end{tabular}

Table 2

Size of collected mussels.

\begin{tabular}{|lllll|}
\hline Sample no & \multicolumn{3}{l}{ Cultured mussel } & Wild mussel \\
\cline { 2 - 5 } & Width $(\mathbf{c m})$ & Length $(\mathbf{c m})$ & Width $(\mathbf{c m})$ & Length $(\mathbf{c m})$ \\
\hline 1 & $3.98 \pm 0.13$ & $8.63 \pm 0.50$ & $2.78 \pm 0.29$ & $6.52 \pm 0.29$ \\
\hline 2 & $3.82 \pm 0.08$ & $8.88 \pm 0.68$ & $3.05 \pm 0.15$ & $6.70 \pm 0.12$ \\
\hline 3 & $3.68 \pm 0.03$ & $7.95 \pm 0.43$ & $2.48 \pm 0.13$ & $5.46 \pm 0.29$ \\
\hline 4 & $3.60 \pm 0.00$ & $8.30 \pm 0.17$ & $2.36 \pm 0.17$ & $5.36 \pm 0.26$ \\
\hline 5 & $3.55 \pm 0.05$ & $7.87 \pm 0.50$ & $2.49 \pm 0.24$ & $5.49 \pm 0.19$ \\
\hline 6 & $3.40 \pm 0.00$ & $7.90 \pm 0.39$ & $2.40 \pm 0.14$ & $5.29 \pm 0.27$ \\
\hline 7 & $3.40 \pm 0.00$ & $7.80 \pm 0.56$ & $2.59 \pm 0.25$ & $5.81 \pm 0.49$ \\
\hline 8 & $3.30 \pm 0.00$ & $7.98 \pm 0.03$ & $2.64 \pm 0.09$ & $5.84 \pm 0.26$ \\
\hline 9 & $3.30 \pm 0.00$ & $7.50 \pm 0.28$ & $2.57 \pm 0.12$ & $5.43 \pm 0.28$ \\
\hline 10 & $3.17 \pm 0.08$ & $7.77 \pm 0.33$ & $2.33 \pm 0.16$ & $4.96 \pm 0.48$ \\
\hline 11 & $3.10 \pm 0.00$ & $7.85 \pm 0.00$ & $2.34 \pm 0.18$ & $4.96 \pm 0.30$ \\
\hline The data was recorded in mean \pm standard deviation. & \\
\hline
\end{tabular}




\subsection{Trends of microplastic pollution at estuarine of Sungai Laloh}

The microplastic observed was classified into threadlike and fragment as shows in the Figure 7. The trends of microplastic show similar between cultured and wild mussel. The most abundance in each mussel were from fragment microplastic. This might because of plastic debris have different density range where polypropylene (PP) and polyethylene (PE) have density $<1.0 \mathrm{~g} / \mathrm{cm}^{3}$. Due to its low density cause it able to float in high water salinity. Some of the product from this polymer was plastic bottle which can break to fragment form. Mussels have more ability to feed fragment plastic that float on the surface of waters. Besides, fragment type was found abundant in wild fishes while threadlike was higher cage-cultured fishes at Setiu Wetland (Ibrahim et al., 2017)

However, the trends were vice versa for sediment sample. Thread like microplastic was most likely present in the sediment sample for both sampling location. In contrast, fibres made up from polyamides more denser in water with density of $1.38 \mathrm{~g} / \mathrm{cm}^{3}$ (Quinn et al., 2017). Polyamides is widely use in fabrication and textiles due its high durability and strength. The study of microplastic in sediment from Skudai and Tebrau river show 3 different shape of microplastic present. The shape includes fragment, threadlike and film (Shazani et al., 2018). The research on microplastic from urban estuary in Tasmania, Australia show that from sediment samples the fibres was detected most abundance total percentage of $87 \%$ (Willis et al., 2017). The detail image of microplastic observed under the microscope is shown in Figure 8.

\subsection{Physical characterization of microplastic}

The observed microplastic were characterize based on color and size. The details are explained in the following section.

\subsubsection{Color}

The microplastics are categorized to 7 color which are black, white, red, blue, yellow, green and other (Yusof et al.,2017). As show in Figure 9, the red color is the most abundance in mussel with percentages of $51.22 \%$ and $44.71 \%$. The second color present abundance on microplastic for cultured and wild mussel sample was blue with percentage of $23.47 \%$ and $27.40 \%$ each. In comparison, green color shows lowest percentage in cultured mussel while white color was absent in wild mussel. In sediment sample, both locations show white color microplastic was most abundant followed by red with percentages of $28.57 \% ; 33.33 \%$ and $17.14 \% ; 25 \%$ respectively. Yellow color has the lowest percentage of $2.86 \%$ for cultured location while black and yellow was absent in wild location.

Black colour microplastic was found in abundant cultured and wild L. calcarifer of Setiu Wetlands (Yusof et al.,2017). Coloured microplastic was reported the most found in three urban estuaries in China (Minjiang, Jiaojiang and Oujiang) followed by black or transparent colour. White colour plastic has recorded the lowest fraction. Colour plastics was cheap compared to colourless or clear plastics. Usually, 
colour plastics is added into the bulk of resins for be moulded and form new materials. Some of predator can mistake ingest food which actually microplastic due to its colour. Besides, coloured plastics was detected in mammals and reptiles include birds, fishs and turtles (Zhao, Zhu and Li, 2015).

\subsubsection{Size}

Microplastics have the size of less than $5 \mathrm{~mm}$. Table 3 show the details size of microplastic found. From the data, the mussel and sediment not only size in micro range but also bigger than that $(>5 \mathrm{~mm})$. The biggest size of threadlike and fragment plastic was found in cultured mussel with length $11.05 \mathrm{~mm}$ and $11.71 \mathrm{~mm}$ respectively. The shortest length was identified around $0.1 \mathrm{~mm}$ for threadlike) and $0.02 \mathrm{~mm}$ for fragment in wild mussels. However, most of the sample present of microplastic size. In North Sea, the size plastic between 0.2 to $4.8 \mathrm{~mm}$ found in fish with percentage $2.6 \%$ from 1,203 fish (Zhao et al., 2015). The abundant of large microplastic was identified in beaches at Bu-An, Korea with amount 12,180 particles $/ \mathrm{m}^{2}$ (Lee et al., 2015).

Table 3

Size of microplastics in the samples.

\begin{tabular}{|lllll|}
\hline \multicolumn{5}{|c|}{ Size range (mm) } \\
\hline & Sampling Point 1 & \multicolumn{2}{l|}{ Sampling Point 2 } \\
\hline & Cultured mussel & Sediment & Wild mussel & Sediment \\
\hline Threadlike: & & & & \\
\hline Black & $0.32-6.47$ & $0.68-2.05$ & $0.10-10.00$ & - \\
\hline White & $1.22-10.09$ & $0.69-3.22$ & - & $1.03-10.04$ \\
\hline Red & $0.77-7.05$ & $0.76-1.71$ & 1.55 & - \\
\hline Blue & $0.20-7.90$ & 0.68 & $0.32-2.66$ & 2.33 \\
\hline Yellow & $2.21-10.48$ & - & - & - \\
\hline Green & $1.50-11.05$ & 1.07 & 1.38 & $2.56-5.59$ \\
\hline Other & $0.32-2.64$ & - & 0.46 & 0.75 \\
\hline Fragment: & & & & \\
\hline Red & $0.02-2.65$ & $0.05-0.39$ & $0.02-2.14$ & $0.08-0.34$ \\
\hline Blue & $0.03-3.81$ & $0.10-0.19$ & $0.11-0.44$ & - \\
\hline Clear/ film & $1.54-11.71$ & $2.48-3.61$ & - & $0.62-1.47$ \\
\hline
\end{tabular}

\subsection{Polymer microplastic present in estuarine ecosystem}

Five (5) selected microplastics from different physical characteristic were selected for performed ATR FTIR as show in Figure 10. The result of absorption bands was compared with previous findings as shown 
in Table 4 to determine the type of polymer present. The polymer found were polypropylene (PP), polyethylene (PP), polyethylene terephthalate (PET), ethylene vinyl acetate (EVA) and nylon (all polyamides). PP, PE, polyvinylchloride (PVC) and polytetrafluoroethylene (PTFE) was found in urban estuaries at China (Zhao et al., 2015).

\subsection{The most polluted mussel}

Comparison of abundance microplastic percentage in mussel was made to identify the most polluted sample as show in the Figure 11. The cultured mussels were collected on 26th October 2020 while the wild mussels were collected on 15th November 2020. In comparison, culture has a highest percentage of microplastic present with amount $70 \%$ compared to wild mussel with only $30 \%$. Therefore, the cultured mussel that located at estuarine of Sungai Laloh was the most polluted. This might affect by waters flow from freshwater region and the use materials for cultured purpose.

Besides, previous findings on 2016 have shown that this area was also contaminated with heavy metal. Based on the accumulation of heavy metal in sediment that located within this cultured area, the concentration of copper (Cu) present was $146.5 \mu \mathrm{g} / \mathrm{g}$ and the highest compared to other point. In addition, zinc $(\mathrm{Zn})$ concentration present was almost similar to the point that has highest concentration with amount $520.2 \mu \mathrm{g} / \mathrm{g}$ (Farah et al., 2016). In addition, P. viridis from Kampung Pasir Putih has been found accumulate with heavy metal. The analysis on mussels was conducted to identify the concentration of 4 heavy metals which are lead $(\mathrm{Pb})$, cadmium $(\mathrm{Cd})$, copper $(\mathrm{Cu})$ and mercury $(\mathrm{Hg})$. Result show that $\mathrm{Pb}$ and $\mathrm{Cd}$ have exceeded the maximum allowable limit of Food Act 1983 Regulations 2013 with concentration 25.10-38.60 $\mu \mathrm{g} / \mathrm{g}$ and 9.10-13.00 $\mu \mathrm{g} / \mathrm{g}$ (Mahat et al., 2018).

\subsection{The correlation of microplastic in mussel at estuarine of Sungai Laloh}

The statistical analysis was used to identify linear regression of the sample from both sampling point. Parametric analysis (paired T-test) was used to identify any difference between the mussel sample. Based on the evaluation, data obtained from sampling Point 1 for cultured mussel was normally distributed with significant value to $p>0.05$. In addition, data obtained from sampling Point 2 show an almost similar trend and normally distributed ( $p>0.05)$. However, based on the T-test the cultured and wild mussel have slightly no significant different $(p>0.05)$.

\subsection{Conclusion}

In this study, microplastics were found present in mussel and sediment sample at the estuarine ecosystem of Sungai Laloh, Pasir Putih. It can be concluded that

1) Trends of microplastic in this ecosystem show that fragment microplastic was most abundant in mussel while threadlike microplastic was most abundant in sediment with percentage of $>50 \%$ each. 
2) Red color microplastic presented higher in mussel while for sediment the white color is the most abundant. Most size of plastics particle or marine debris in the sample was in microplastic.

3) Microplastic that cause pollution to this ecosystem were from polymer group of polypropylenes (PP), polyethylene (PE), Polyethylene terephthalate (PET), ethylene vinyl acetate (EVA) and nylon.

4) In comparison, cultured mussel was more polluted with $70 \%$ of microplastic present while wild mussel was only $30 \%$.

5) Microplastic in cultured and wild mussels have no significant difference ( $p>0.05)$.

\section{Recommendation}

The study only provided data on microplastics pollution at one Point location for each mussel causing limited data presented. Due to time constraint during movement control order (MCO), the scope of present study may cause underestimation of the extent microplastic contamination at the estuarine ecosystem of Sungai Laloh, Pasir Putih. The following recommendations can be considered for future studies:

1) Select the same sizes of cultured and wild mussel to improve data accuracy and reduce bias. Besides, dry mussels can be used.

2) Conduct a long period for sampling to ensure actual data presentation on the extend microplastic pollution.

3) Select more sampling stations to improve data accuracy.

\section{Declarations}

\section{Statements and Declarations}

The authors declare that no funds, grants or other supportive were received during the preparation of this paper.

\section{References}

1. Alam FC, Sembiring E, Muntalif BS, Suendo V (2019) Microplastic distribution in surface water and sediment river around slum and industrial area (case study: Ciwalengke River, Majalaya district, Indonesia). Chemosphere 224:637-645

2. Athey SNA, Samantha D, Gordon CA, Monteleone B, Seaton P, Andrady AL, Taylor AR, Brander SM (2020) Trophic transfer of microplastics in an estuarine food chain and the effects of a sorbed legacy pollutant. Limnol Oceanogr Lett 5(1):154-162

3. Cai H, Du F, Li L, Li B, Li J, Shi H (2019) A practical approach based on FT-IR spectroscopy for identification of semi-synthetic and natural celluloses in microplastic investigation. Sci Total Environ 669:692-701

4. Defu H, Yongming L, Shibo L, Mengting L, Yang S, Lili L (2018) Microplastics in soils: Analytical methods, pollution characteristics and ecological risks. TRAC Trends Anal Chem 109:163-172 
5. Deng J, Guo P, Zhang X, Su H, Zhang Y, Wu Y, Li Y (2020) Microplastics and accumulated heavy metals in restored mangrove wetland surface sediments at Jinjiang Estuary (Fujian, China). Mar Pollut Bull 159:111482

6. Dowarah K, Patchaiyappan A, Thirunavukkarasu C, Jayakumar S, Devipriya SP (2020) Quantification of microplastics using Nile Red in two bivalve species Perna viridis and Meretrix meretrix from three estuaries in Pondicherry, India and microplastic uptake by local communities through bivalve diet. Mar Pollut Bull 153:110982

7. Firdaus MT, Lestari Y, P (2020) Microplastic pollution in the sediment of Jagir Estuary, Surabaya City, Indonesia. Mar Pollut Bull 150:110790

8. Han MN, Tang X, Zhang M, Wang BT, Yue G, Kong W, Zhu X, J (2020) Distribution of microplastics in surface water of the lower Yellow River near estuary. Sci Total Environ 707:135601

9. Ibrahim YS, Rathnam R, Anuar ST, Khalik WMAWM (2017) Isolation and Characterisation of Microplastic Abundance in Lates calcarifer from Setiu Wetlands, Malaysia.Malaysian Journal of Analytical Science, 21(5)

10. Jung M, Horgen D, Orski S, Rodriguez V, Beers K, Balazs G, Lynch J (2018) Validation of ATR FT-IR to Identify Polymers of Plastic Marine Debris, Including Those Ingested by Marine Organisms. Marine Pollution Bulletin, 127

11. Lee J, Lee JS, Jang YC, Hong SY, Shim WJ, Song YK, Hong S (2015) Distribution and Size Relationships of Plastic Marine Debris on Beaches in South Korea. Arch Environ Contam Toxicol 69(3):288-298

12. Maadin FS, Rahman MFaedzwanA, Zawawi MAA, Azman S, Oladokun S (2016) Copper and Zinc Accumulation in Sediment at Straits of Johor.Malaysian Journal of Civil Engineering, 28(3)

13. Mahat NA, Muktar NK, Ismail R, Abdul Razak FI, Wahab A, Keyon A, A. S (2018) Toxic metals in Perna viridis mussel and surface seawater in Pasir Gudang coastal area, Malaysia, and its health implications. Environ Sci Pollut Res Int 25(30):30224-30235

14. Nishida A, Ohkawa K, Ueda I, Yamamoto H (2003) Green mussel Perna viridis L.: attachment behaviour and preparation of antifouling surfaces. Biomol Eng 20(4-6):381-387

15. Quinn B, Murphy F, Ewins C (2017) Validation of density separation for the rapid recovery of microplastics from sediment. Anal Methods 9(9):1491-1498

16. Revel M, Yakovenko N, Caley T, Guillet C, Chatel A, Mouneyrac C (2020) Accumulation and immunotoxicity of microplastics in the estuarine worm Hediste diversicolor in environmentally relevant conditions of exposure. Environ Sci Pollut Res Int 27(4):3574-3583

17. Shazani S, Shamila A, Mohd SMI, Yusrina A, Farhan ZN, Zurairahetty, Syahrizal I (2018) Microplastics in sediment from Skudai and Tebrau river, Malaysia: a preliminary study. MATEC Web of Conferences, 250

18. Su L, Cai H, Kolandhasamy P, Wu C, Rochman CM, Shi H (2018) Using the Asian clam as an indicator of microplastic pollution in freshwater ecosystems. Environ Pollut 234:347-355 
19. Tan K, Soon JR (2014) A Review of Feeding Behavior, Growth, Reproduction and Aquaculture Site Selection for Green-Lipped Mussel, Perna viridis. Adv Bioscience Biotechnol 5:462-469

20. Wagner CS, Alvarez-Muñoz D, Brennholt N, Bourrain X, Buchinger S, Fries E Cécile Grosbois, Jörg Klasmeier, Teresa Marti, Sara Rodriguez-Mozaz, Ralph Urbatzka, A Dick Vethaak, Margrethe WintherNielsen and Georg Reifferscheid. (2014). Microplastics in freshwater ecosystems: what we know and what we need to know. Environmental Sciences Europe 26:12

21. Waite HR, Donnelly MJ, Walters LJ (2018) Quantity and types of microplastics in the organic tissues of the eastern oyster Crassostrea virginica and Atlantic mud crab Panopeus herbstii from a Florida estuary. Mar Pollut Bull 129(1):179-185

22. Wang S, Xue N, Li W, Zhang D, Pan X, Luo Y (2020) Selectively enrichment of antibiotics and ARGs by microplastics in river, estuary and marine waters. Sci Total Environ 708:134594

23. Willis KA, Eriksen R, Wilcox C, Hardesty BD (2017) Microplastic Distribution at Different Sediment Depths in an Urban Estuary.Frontiers in Marine Science, 4

24. Wu NZ, Zhao Y, He Z, Li J, Li W, Xu J, Ma W, Niu Y, Z (2020) Colonization characteristics of bacterial communities on microplastics compared with ambient environments (water and sediment) in Haihe Estuary. Sci Total Environ 708:134876

25. Yulin H, Mengyue G, Jiayi W, Amarjeet B (2019) Current research trends on microplastic pollution from wastewater systems: a critical review. Reviews in Environmental Science and Bio/Technology 18(2):207-230

26. Zhao S, Zhu L, Li D (2015) Microplastic in Three Urban Estuaries, China. Environ Pollution 206:597604

27. Zuo L, Sun Y, Li H, Hu Y, Lin L, Peng J, Xu X (2020) Microplastics in mangrove sediments of the Pearl River Estuary, South China: Correlation with halogenated flame retardants' levels. Sci Total Environ 725:138344

\section{Tables}

Tables $3 \& 4$ are available in the Supplementary Files section.

\section{Figures}


Preparation of mussel and sediment sample.

Sampling location: Sungai Laloh, Pasir Putih.

Pre-treatment/ density separation:

i) Each of sample was placed into $250 \mathrm{~mL}$ conical flask and added with saturated sodium chloride solution $(\mathrm{NaCl})$.

Sample digestion:

i) $100 \mathrm{~mL}$ of $35 \%$ hydrogen peroxide $\left(\mathrm{H}_{2} \mathrm{O}_{2}\right)$ was added. Then, the open part of flask was sealed with aluminium foil to prevent airborne microplastic contamination.

ii) The sample was incubated in incubator shaker for 24 to 48 hours with condition of $50^{\circ} \mathrm{C}$ and $80 \mathrm{rpm}$ until the tissue is break down.

iii) The sample was filtered by using vacuum pump and microfiber glass filter $\mathrm{GF} / \mathrm{C}$ grade.

Analyses to identify and characterize the microplastics by using:

i) Stereomicroscope HSZ 600

ii) ATR FT-IR

iii) Statistical software

Figure 1

Summary process of research methodology. 


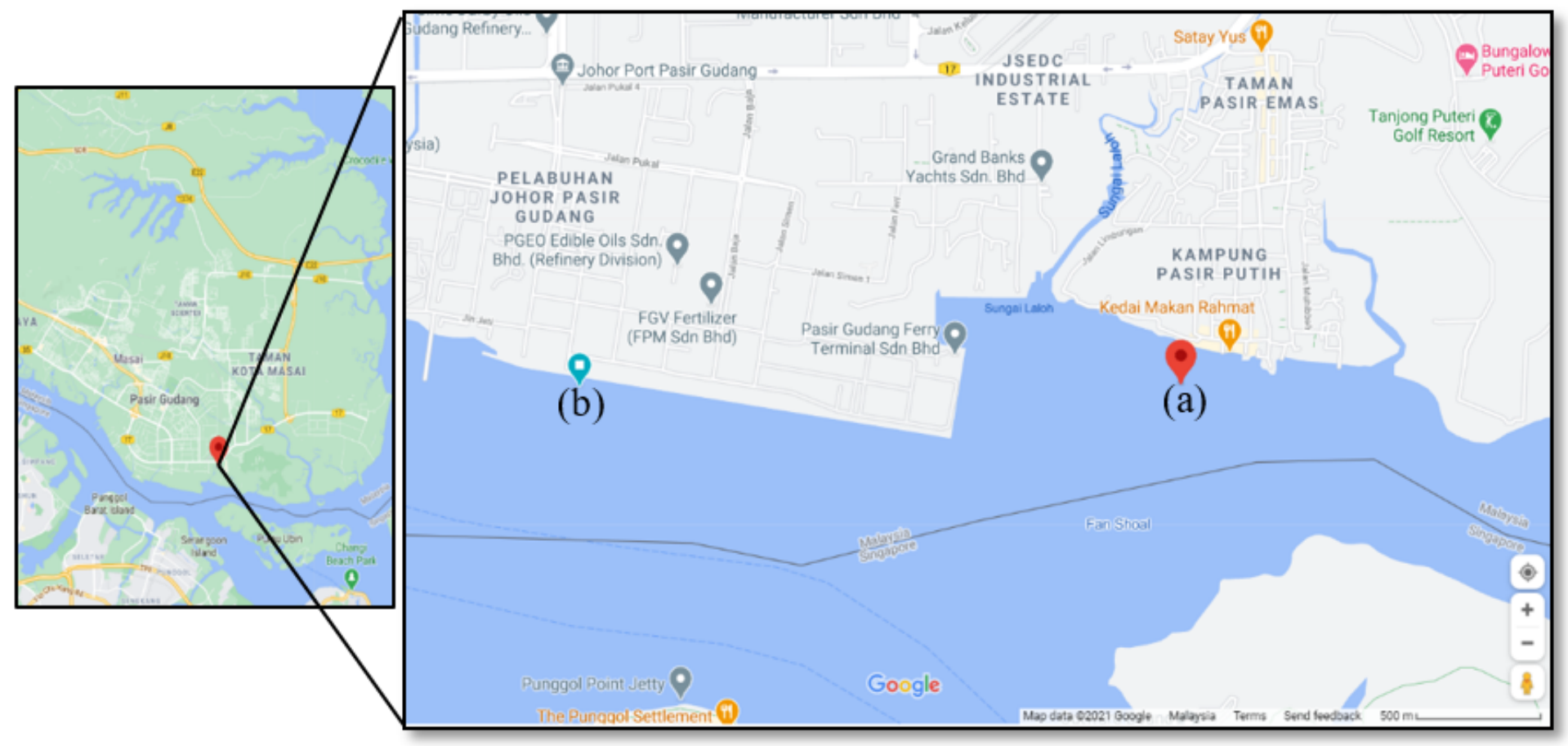

Figure 2

The location of sampling point at estuarine ecosystem near to Sungai Laloh, (a) Point 1 (cultured mussel) and (b) Point 2 (wild mussel).

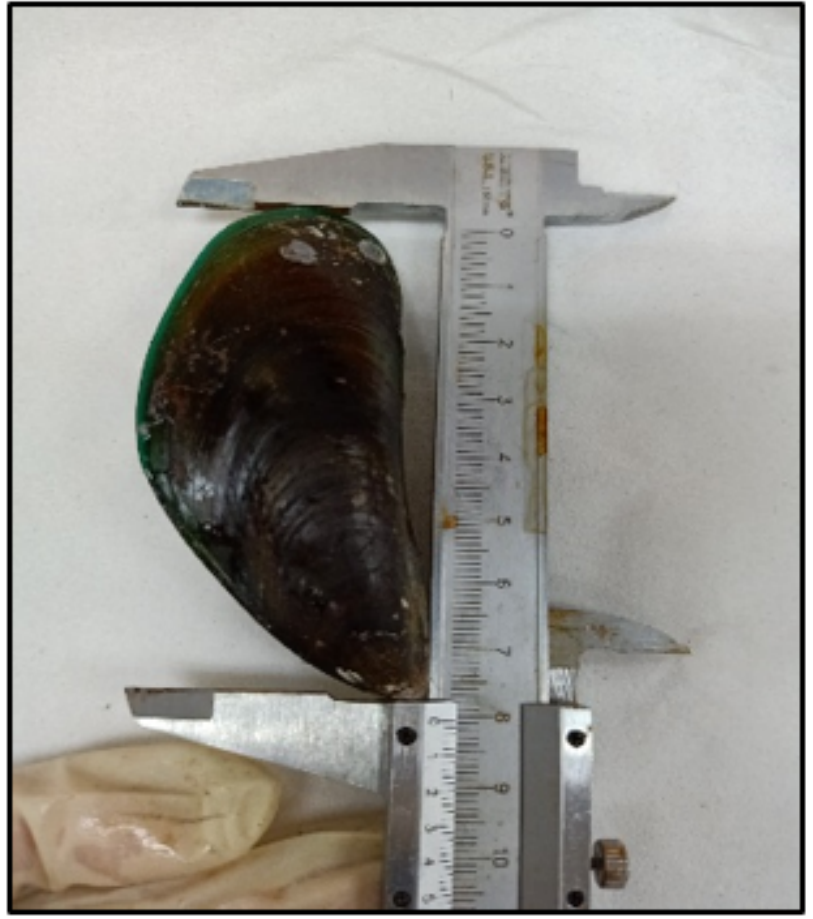

(a)

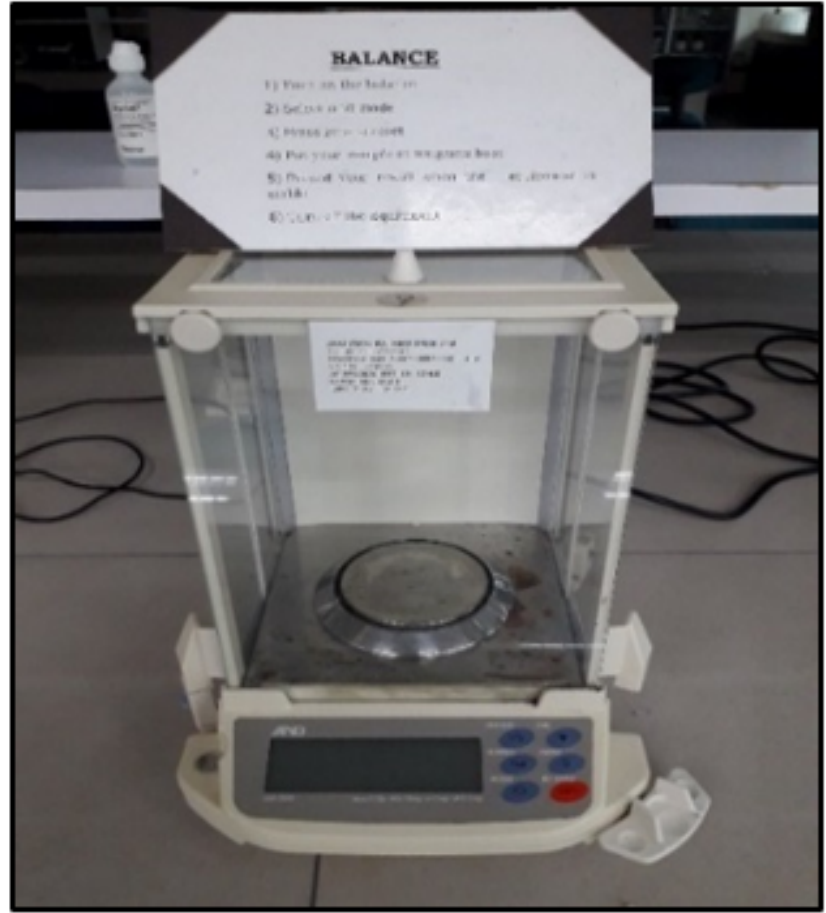

(b)

Figure 3 
(a) Vernier calipers to measure the size of mussel and (b) analytical balance to measure the weight of mussel.

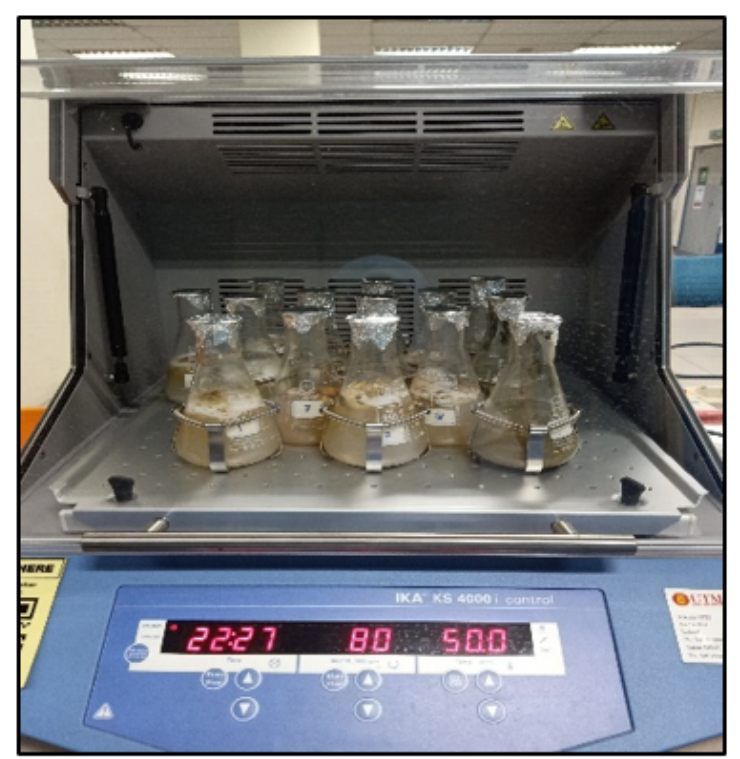

(a)

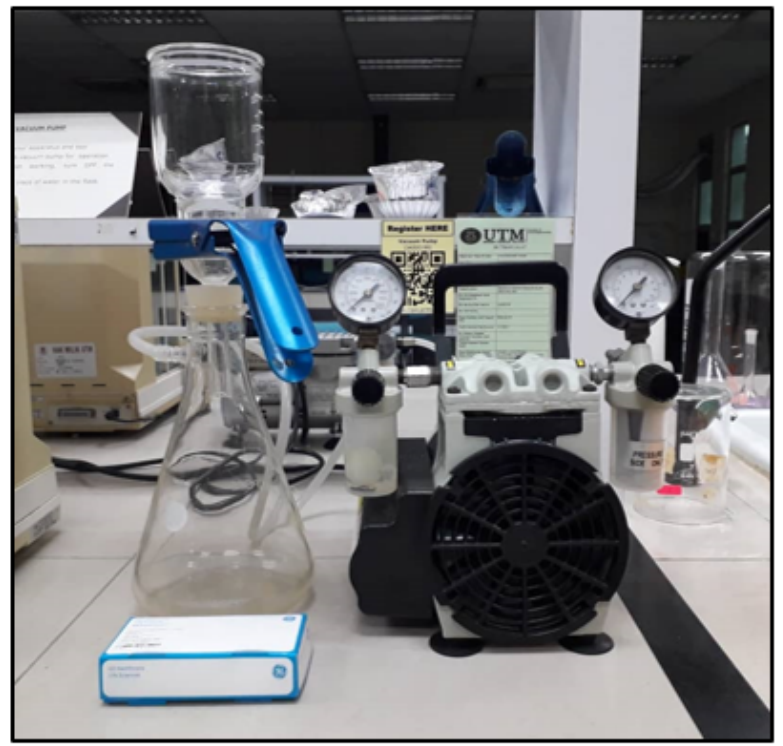

(b)

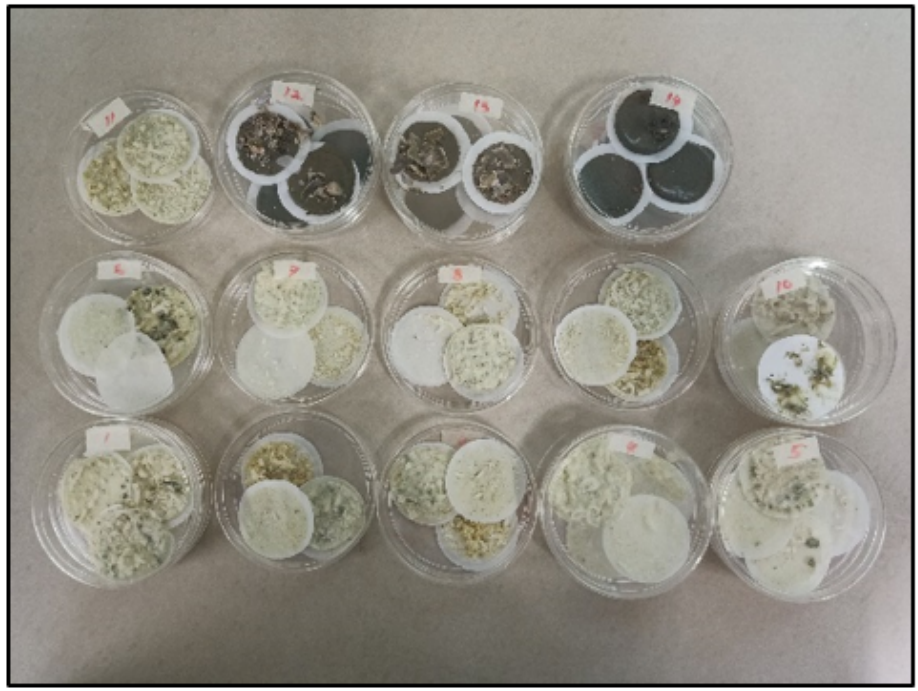

(c)

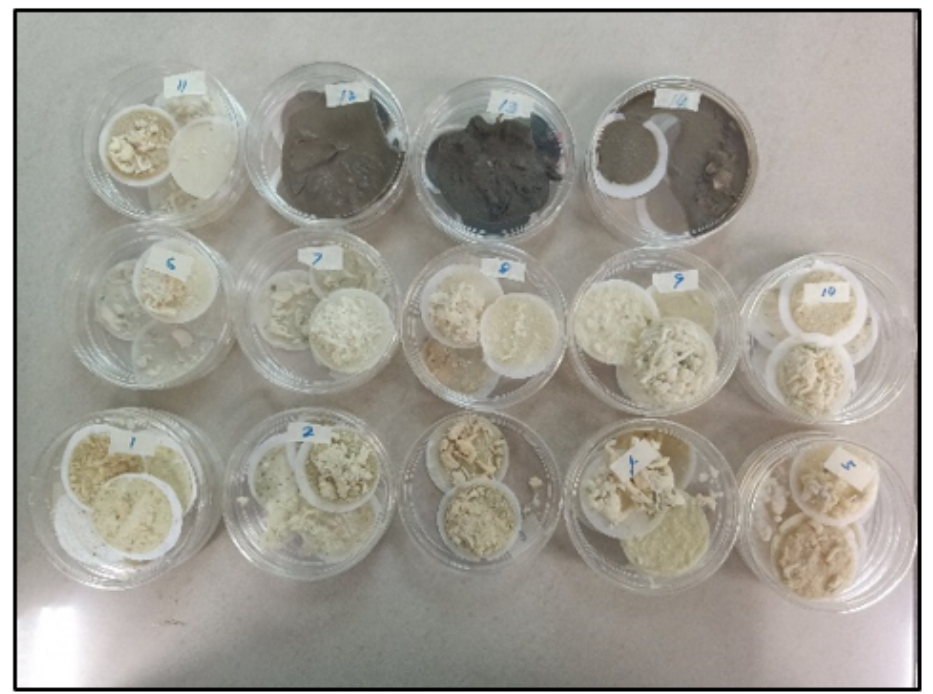

(d)

Figure 4

(a) Incubator shaker used for sample digestion, (b) materials and apparatus used in the filtration process,

(c) all replicate sample of wild mussels and sediment placed in petri dish after be filtered and (d) cultured mussels and sediment sample after be filtered. 


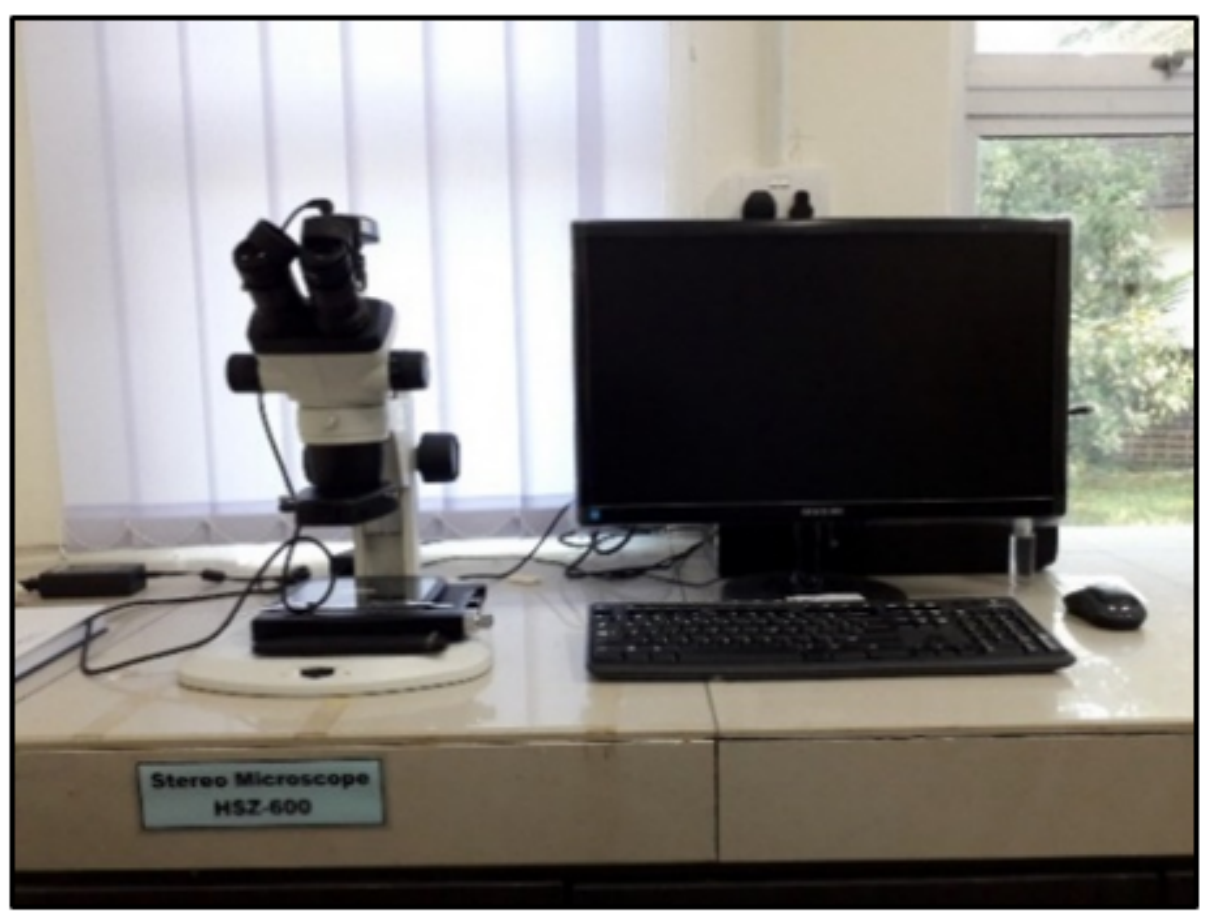

Figure 5

Stereomicroscope HSZ 600 Series.

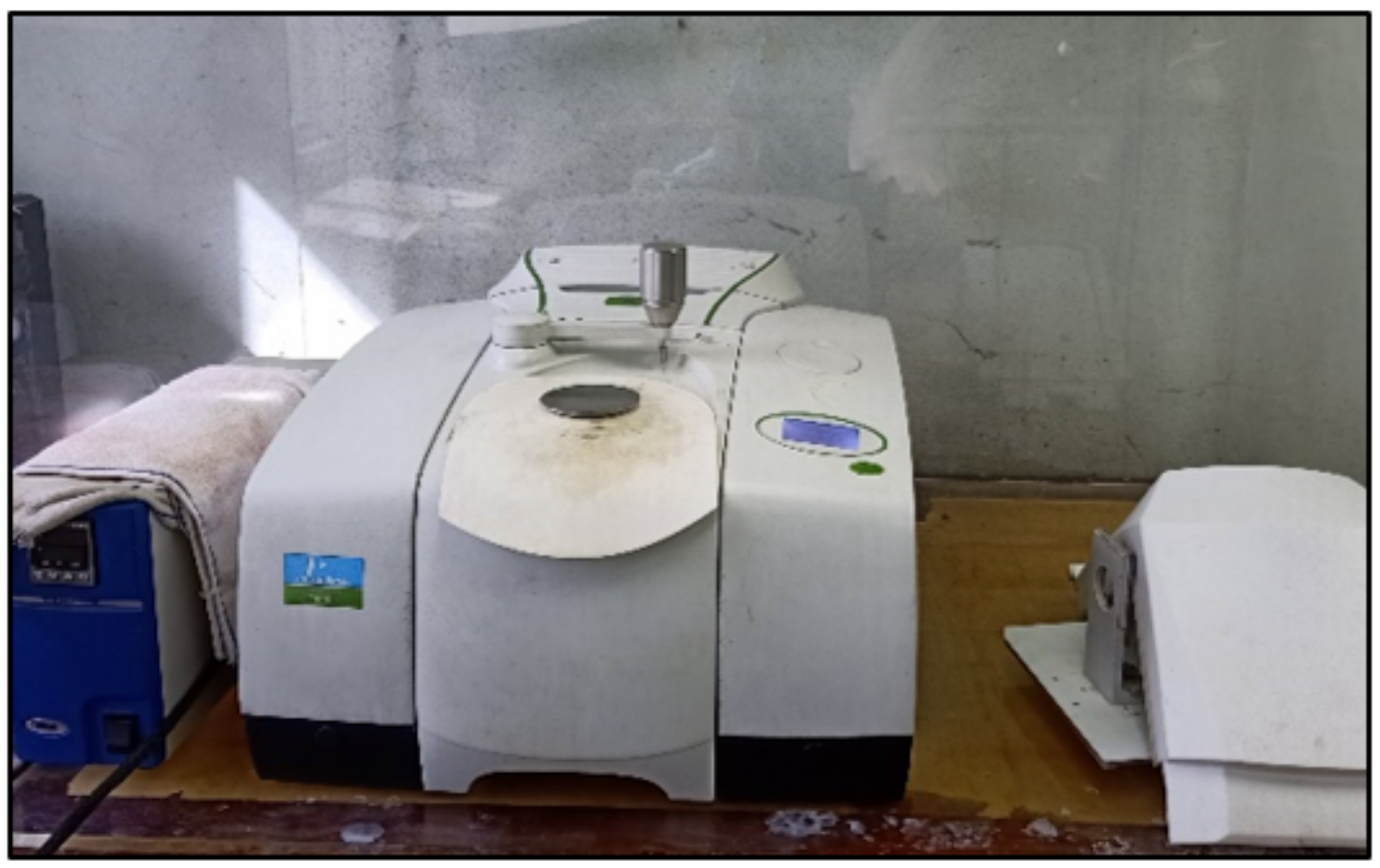

Figure 6

Perkin Elmer Frontier ATR FT-IR. 


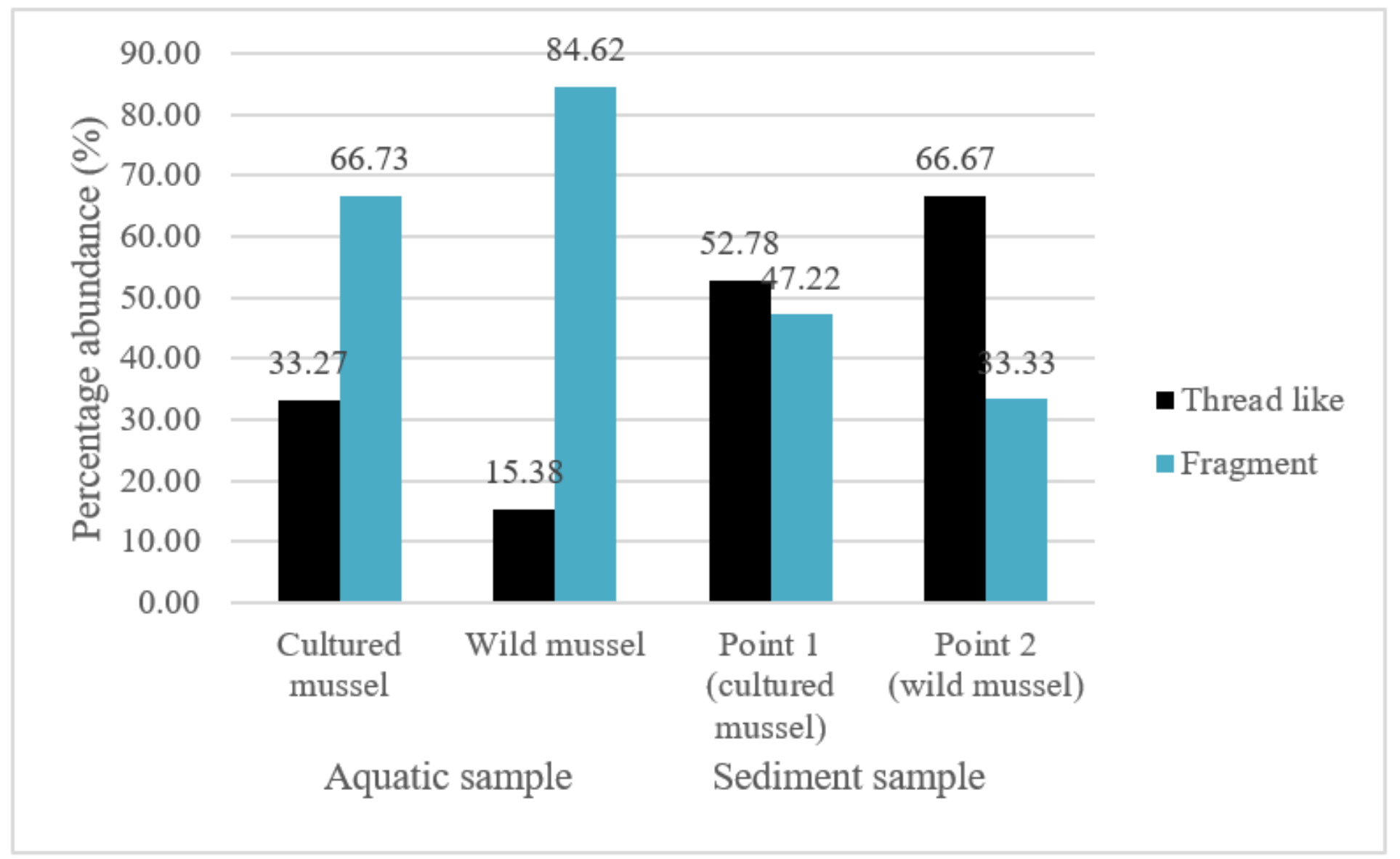

Figure 7

Trends of microplastic found in mussels and sediments. 


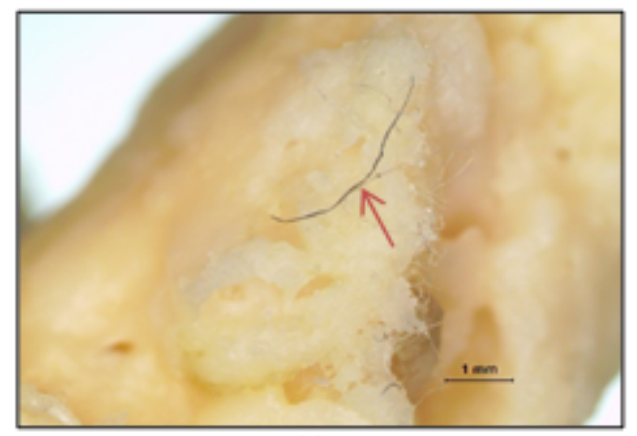

(a)

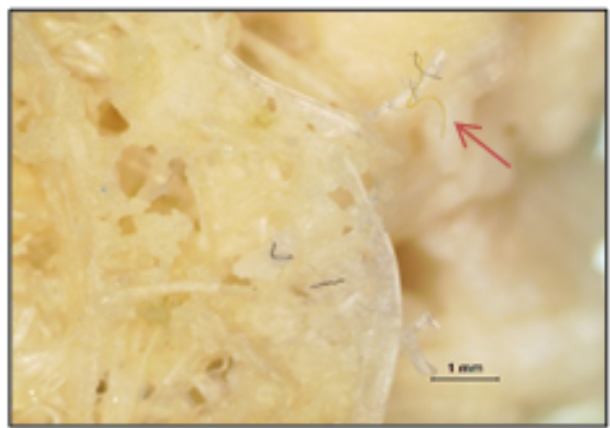

(c)

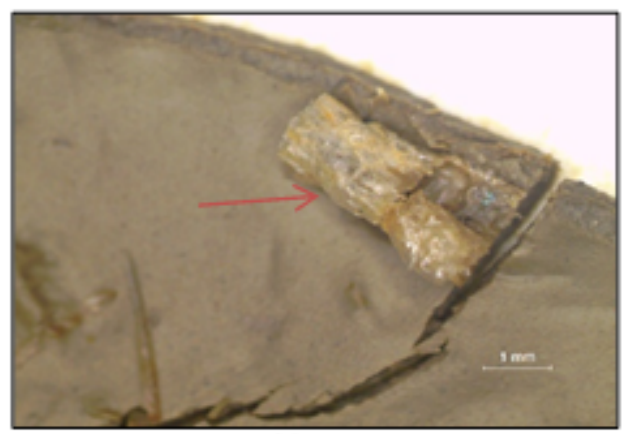

(e)

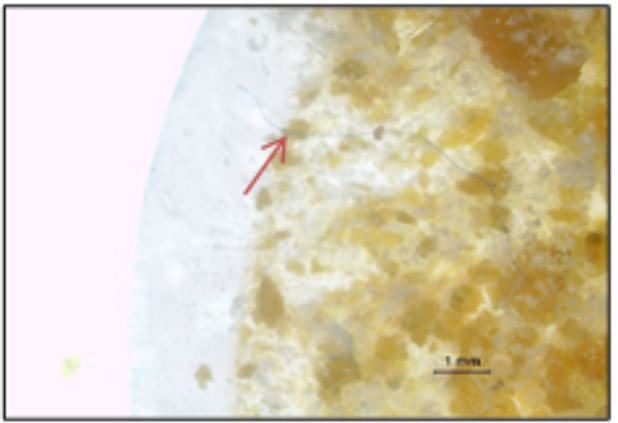

(b)

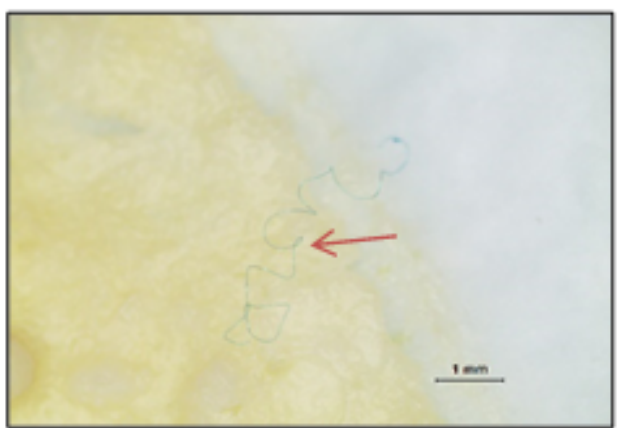

(d)

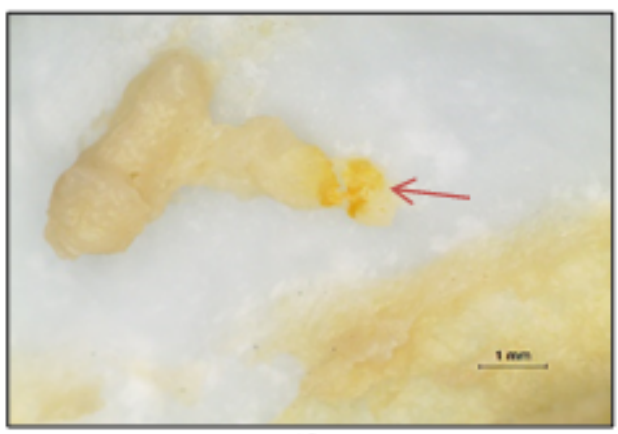

(f)

Figure 8

Red arrow show the threadlike microplastic(a) black (b) blue (c) yellow (d) green and fragment microplastic (e) clear/ film (f) yellow. 


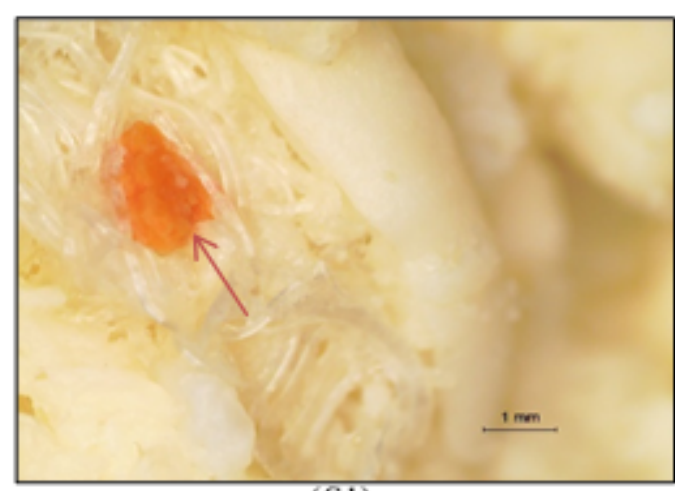

(S1)

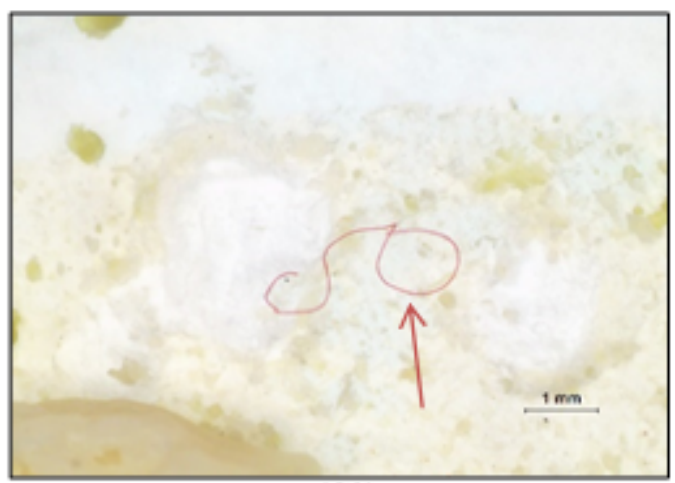

(S3)

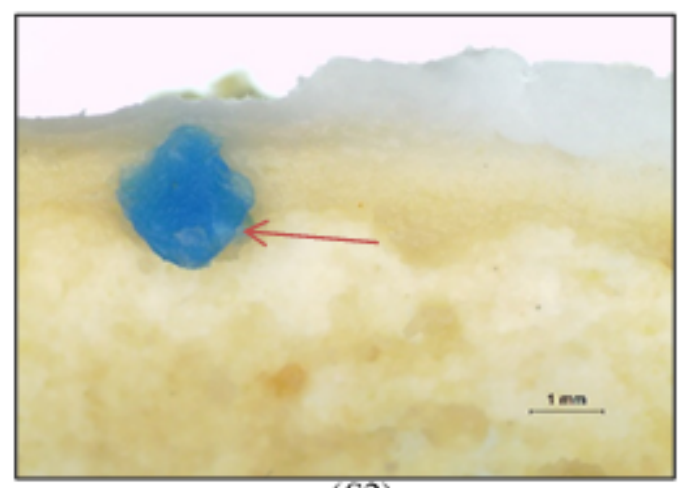

(S2)

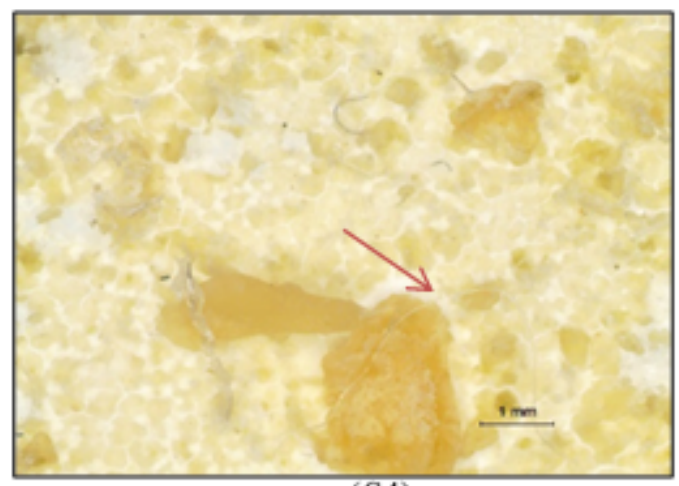

(S4)

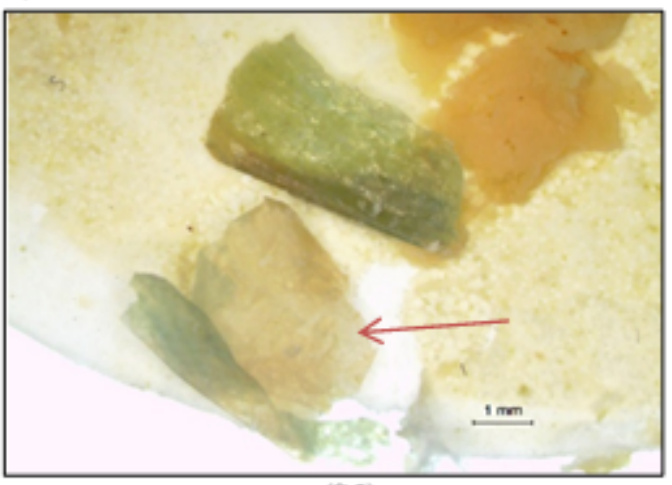

(S5)

Figure 9

Characterization of microplastic based on color. 


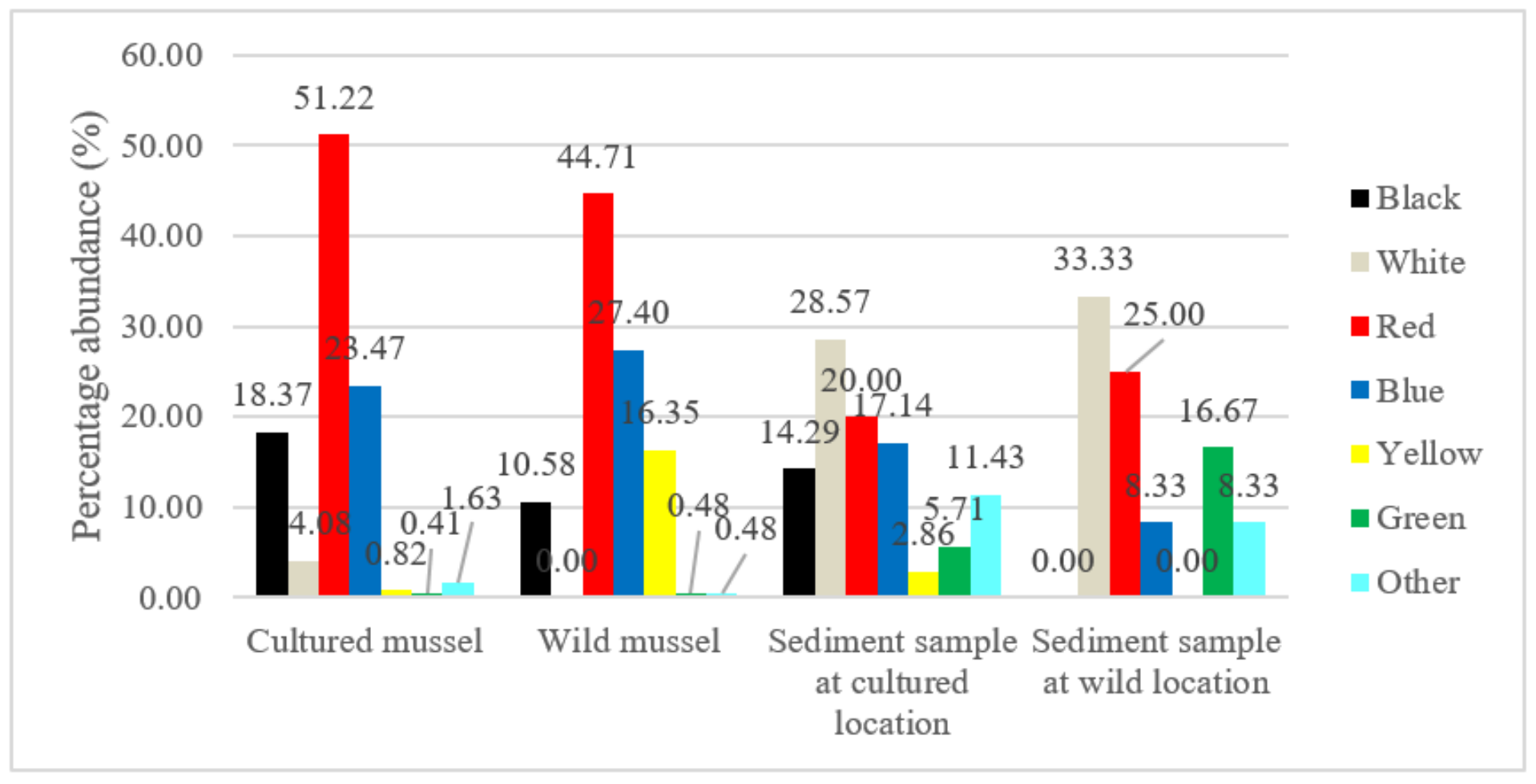

Figure 10

Red arrow show the selected microplastic for obtained ATR FT-IR result (S1) red fragment, (S2) blue fragment, (S3) red thread, (S4) clear threadlike and (S5) film/ clear fragment.

\section{Comparison of microplastic abundance in mussels}

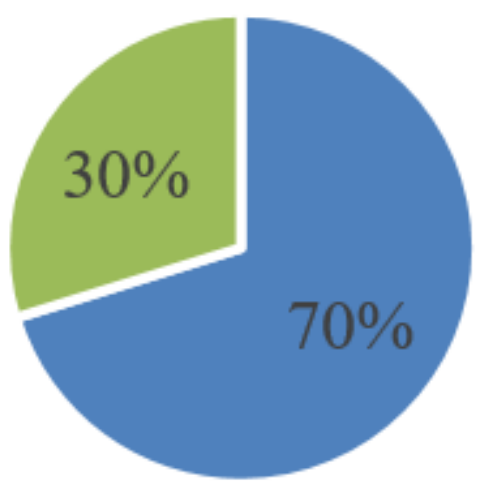

- Aquaculture

- Wild

Figure 11 
Percentage abundance of microplastic in mussel sample.

\section{Supplementary Files}

This is a list of supplementary files associated with this preprint. Click to download.

- Table45.docx 